\title{
Perlindungan Hukum Bagi Pengungsi di Negara Ketiga: Praktik Indonesia
}

\author{
Fitria*
}

\begin{abstract}
Abstrak
Setiap orang selalu berupaya memiliki kehidupan yang aman, damai, dan sejahtera dimana hak dan kebebasannya dijamin negara. Sayangnya, sampai saat ini masih terjadi konflik atau kegagalan negara dalam mewujudkan hal tersebut bagi warga negaranya. Hal tersebutlah yang menyebabkan orang-orang yang tidak terpenuhi haknya kemudian mencari suaka ke negara-negara yang dapat memberikan apa yang mereka inginkan, yaitu negara maju. Upaya mencari suaka yang dilakukan dengan segala keterbatasan menyebabkan para pencari suaka dalam perjalanannya terhenti dan bahkan menetap selamanya di negara ketiga. Dalam hukum internasional, perlindungan atas pencari suaka dan pengungsi diakomodasi oleh Konvensi Pengungsi 1951. Permasalahannya, negara ketiga yang sering menjadi tempat pemberhentian bahkan penampungan pencari suaka dan pengungsi kebanyakan tidak meratifikasi konvensi tersebut, meskipun setiap negara mengakui prinsip non-refoulement bagi pengungsi dan pencari suaka sebagai kebiasaan internasional, termasuk Indonesia. Tulisan ini mengkaji praktik perlindungan dan tindakan lainnya yang dilakukan Indonesia dalam menangani permasalahan pengungsi di wilayah NKRI sebagai negara non-peratifikasi, termasuk keterlibatan dan kerjasama organisasi internasional seperti IOM dan UNHCR.
\end{abstract}

Kata kunci: IOM, Konvensi Pengungsi, perlindungan pengungsi, prinsip non-refoulement, UNHCR.

\section{Refugees Protection in Thirld World Countries: Indonesian Practices}

\begin{abstract}
Every person tends to strive for having a safe, peaceful, and prosperous life in which their rights and freedom are guaranteed by the state. Unfortunately, conflicts or state failures on realizing its citizens' rights still occur untill now. This is becoming the sole reason why people seek asylum in countries that may provide their rights, namely the developed countries. Lack of logistic support caused asylum seekers to stop and even settled permanently in a third country. In international law, the protection of asylum seekers and refugees are regulated by the 1951 Refugee Convention. The problem comes up as the third countries which often become shelters or even dismissal places of asylum seekers and refugees mostly have not ratified the convention, even though the non-refoulement principle for refugees and asylum seekers is recognized as an international customary law (including Indonesia). This article assess the protection and the other acts undertaken by Indonesian government on refugees and asylum seekers issue as a non-state parties to the 1951 Refugee Convention, including

PADJADJARAN Jurnal IImu Hukum Volume 2 Nomor 1 Tahun 2015 [ISSN 2460-1543] [e-ISSN 2442-9325]

* Fakultas Syariah dan Hukum UIN Syarif Hidayatullah, Jalan Ir. H. Juanda 95 Ciputat, Jakarta, pia_bondowoso@yahoo.com, S.H. (Universitas Diponegoro), LL.M. (Catholic University of Lyon).

1 Portal Nasional Republik Indonesia, "Geografi Indonesia", http://www.indonesia.go.id/in/sekilasindonesia/geografi-indonesia, diakses 1 Oktober 2014.
\end{abstract}


the involvement and cooperation of international organizations such as the IOM and UNHCR.

Keywords: IOM, Refugee Convention, refugee protection, non-refoulement principle, UNHCR.

\section{A. Pendahuluan}

Indonesia adalah negara yang memiliki posisi strategis secara geografis. Indonesia merupakan negara di Asia Tenggara yang terletak di garis khatulistiwa dan berada di antara benua Asia dan Australia serta antara Samudra Pasifik dan Samudra Hindia. Mengingat letaknya yang berada di antara dua benua dan dua samudera, Indonesia disebut juga sebagai nusantara (kepulauan antara). Terdiri dari 17.508 pulau, Indonesia adalah negara kepulauan terbesar di dunia. ${ }^{1}$

Posisi yang sangat strategis tersebut menyebabkan Indonesia menjadi salah satu negara yang sering "dibanjiri" para pencari suaka dan pengungsi. Menurut Data United Nations High Commissioner for Refugees (UNHCR) pada Januari 2012 misalnya, terdapat 3275 pencari suaka dan 1052 pengungsi yang terdaftar di UNHCR Jakarta. Selama Januari terdapat 315 orang terdaftar dengan jumlah pencari suaka terbesar berasal dari Afghanistan (66,6\%), diikuti dengan Iran (9,8\%), dan Somalia $(6,7 \%){ }^{2}$ Selanjutnya sampai akhir tahun 2014 ini, terdapat 4.131 pengungsi yang sebagian besar berasal dari Afghanistan (37\%), Myanmar (21\%), Sri Lanka (8\%) dan Somalia (8\%) yang terdaftar di UNHCR Jakarta. ${ }^{3}$ Ini berarti selama dua tahun, keberadaan pengungsi meningkat pesat lebih dari tiga kali lipat, yaitu dari 1.052 orang menjadi 4.131 orang.

Keberadaan pencari suaka dan pengungsi di Indonesia sebenarnya telah ada sejak puluhan tahun lalu. Pada era kepemimpinan Presiden Soeharto, Indonesia menjadi tujuan pencari suaka dan pengungsi Vietnam pada tahun 1979, tepatnya setelah jatuhnya ibukota Saigon (Vietnam Selatan) ke tangan Vietnam Utara. ${ }^{4}$ Ratusan ribu orang meninggalkan wilayah ini untuk mencari perlindungan di negara lain dengan berbagai cara baik lewat menyusuri sungai, jalur udara, maupun melalui laut. ${ }^{5}$ Gelombang Pengungsi Vietnam yang mendapatkan ancaman di negaranya ini selain menuju ke Indonesia juga memasuki beberapa negara Asia Tenggara lain, seperti Malaysia dan Filipina. Kebijakan Pemerintahan Soeharto ketika itu, pengungsi ini ditempatkan di Pulau Galang, Kabupaten Riau. ${ }^{6}$

2 UNHCR, "Operation Fact Sheet Indonesia”, http://www.unhcr.or.id/images/pdf/pu-blications/operational fact_sheet_indonesia_final.pdf, diunduh 15 September 2014.

3 UNHCR, "Who We Help", http://unhcr.or.id/en/who-we-help/refugees.

4 Atik Krustiyati, Penanganan Pengungsi di Indonesia, Surabaya: Brilian Internasional, 2010, hlm. 18.

5 lihat secara umum, Enny Soeprapto, "Promotion of Refugee in Indonesia", Jurnal Hukum International, Volume 2, Nomor 1, Oktober 2004.

6 Achmad Romsan, (et.al), Pengantar Hukum Pengungsi Internasional: Hukum Internasional dan Prinsip-Prinsip Perlindungan Internasional, Bandung: UNHCR, 2003, hlm. 181-192. 
Eksistensi pengungsi yang telah ada selama puluhan tahun dan terus meningkat dari tahun ke tahun menunjukkan bahwa keberadaannya tidak boleh dinafikkan. Tulisan ini menjelaskan tentang perlindungan pengungsi dan kewajiban negara ketiga terhadap keberadaannya menurut hukum internasional. Selain itu, tulisan ini juga menganalisis keberadaan pengungsi di Indonesia dikaitkan dengan pengaturannya di Indonesia. Tulisan ini merupakan reformulasi hasil laporan penelitian penulis yang tidak terpublikasi, selama periode April-November 2014. Penelitian ini tidak sebatas mengkaji regulasi yang bersifat internasional maupun nasional, namun juga bersumber dari penelitian lapangan dengan mewawancarai pihak-pihak terkait dan penelusuran kondisi pengungsi.

Penulis telah menemukan beberapa tulisan sebelumnya tentang pengungsi di Indonesia. Pertama, tulisan karya Savitri Taylor dan Brynna Rafferty-Brown. ${ }^{7}$ Savitri memaparkan kendala-kendala yang dialami pengungsi dalam memperoleh status sebagai pengungsi melalui UNHCR Perwakilan Indonesia. Savitri juga menggambarkan proses bagaimana pengungsi bisa sampai masuk di Indonesia melalui wawancara mendalam kepada 59 pencari suaka dan pengungsi di Indonesia. Tulisan tersebut dimaksudkan untuk memberikan masukan kepada UNHCR dalam memperbaiki proses pengajuan status pengungsi di Indonesia dan sekaligus kepada Pemerintah Australia dalam mengambil kebijakan dan menjalin kerjasama dengan Pemerintah Indonesia dan UNHCR Indonesia tentang pengungsi di Indonesia.

Tulisan kedua oleh Penelope Mathew dan Tristan Harley berjudul Refugees Protection and Regional Cooperation in Southeast Asia. ${ }^{8}$ Tulisan ini membahas perlindungan terhadap pengungsi di tiga negara, yaitu Malaysia, Thailand dan Indonesia. Tujuan dari tulisan ini adalah memetakan perlindungan pengungsi di ketiga negara serta menguraikan tantangan dan hambatan yang dialami di ketiga negara tersebut.

Selain dua tulisan di atas, penulis juga pernah menulis tentang pengungsi yaitu: Konsep Pencari Suaka dan Pengungsi menurut Undang-Undang No. 5 Tahun 2012 tentang Keimigrasian dan Kebijakan Pemerintah Indonesia tentang Pencari Suaka dan Pengungsi (Studi Kasus Pencari Suaka dan Pengungsi Etnis Rohignya di Indonesia). Tulisan-tulisan di atas telah menjadi sumber inspirasi dan memberikan kontribusi bagi tulisan ini.

7 lihat secara umum, Savitri Taylor and Brynna Rafferty-Brown," Difficult Journeys: Accesing Refugee Protection in Indonesia", Monash University Law Review, Vol. 36, No. 3, 2010.

8 Penelope Mathew dan Tristan Harley, "Refugees Protection and Regional Cooperation In Southeast Asia", A Field Work Research, March 2014, Australian National University (ANU), https://digitalcollec-tions.anu.edu.au/ bitstream/1885/11662/1/Mathew\%20\%26\%20Harley\%20Refugee\%20protection\%202014. pdf. 


\section{B. Pengungsi, Negara Ketiga dan Perlindungannya \\ 1. Definisi Pengungsi}

Pengaturan tentang pengungsi dalam Hukum Internasional tunduk terhadap ketentuan Konvensi Jenewa 1951. Pengungsi menurut Konvensi Pengungsi Tahun 1951:

"As a result of events occurring before 1 January 1951 and owing to wellfounded fear of being persecuted for reasons of race, religion, nationality, membership of a particular social group or political opinion, is outside the country of his nationality and is unable or, owing to such fear, is unwilling to avail himself of the protection of that country; or who, not having a nationality and being outside the country of his former habitual residence as a result of such events, is unable or, owing to such fear, is unwilling to return to it."

Pengungsi adalah seseorang yang mempunyai rasa takut yang beralasan karena rasnya, agamanya, kebangsaannya, keanggotaannya dalam kelompok sosial tertentu atau pandangan politiknya berada di luar negara asalnya, dan tidak dapat atau tidak mau memanfaatkan perlindungan negara asalnya atau kembali ke negara tersebut karena takut terhadap persekusi. ${ }^{9}$

Dirumuskan pada perang dingin, kehadiran Konvensi Pengungsi awal mulanya sebagai harapan dunia barat untuk melindungi pengungsi yang dalam benak mereka sebagai cara untuk mengutuk kekejaman-kekejaman yang dilakukan oleh Blok Timur. Bagi negara-negara barat, pengungsi yang baik adalah pengungsi yang melarikan diri dari komunisme dan bermukim di negara barat. ${ }^{10}$ Seiring berjalannya waktu, Konvensi Pengungsi telah menunjukkan peranannya yang melampaui sekatsekat ideologis perang dingin, dibuktikan dengan banyak negara yang telah meratifikasi Konvensi Pengungsi ini, sebanyak 144 negara yang telah meratifikasi dari 193 negara yang terdaftar di PBB. ${ }^{11}$

Instrumen hukum internasional tersebut tidak memberikan kriteria lebih jauh mengenai pengungsi, sehingga terdapat perbedaan penafsiran mengenai pihak yang dapat dikategorikan sebagai pengungsi. Definisi sempit mengenai pengungsi dipaparkan Matthew Lister sebagai: "The definition covers only those who have a well-founded fear of persecution on the basis of one of the so-called protected grounds". Definisi ini menyiratkan bahwa mereka yang tidak mengalami ketakutan atas persekusi walaupun mengalami berbagai macam penderitaan yang luar biasa

9 Kate Jastram dan Marlyn Achiron, Perlindungan Pengungsi, yang diterjemahkan oleh Enny Suprapto dan Rama Slamet, Jakarta: Komisariat Tinggi Perserikatan Bangsa-Bangsa dan Uni Antar Parlemen, 2004, hlm.19.

10 Lebih lanjut menurut negara Komunis Pengungsi adalah "pengkhianat yang menolak kembali pulang untuk berbakti kepada negaranya.." dalam Stephane Jaquemet, "Mandat dan Fungsi dari Komisariat Tinggi Perserikatan Bangsa-Bangsa (UNHCR)", Jurnal Hukum Internasional Fakultas Hukum Universitas Indonesia, Volume 2, Nomor 1, Oktober 2004, hlm.3.

1 UNHCR, "States Party to The 1951 Convention relating to the Status Refugees and the 1967 Protocol", http://www.unhcr.org/3b73b0d63.html, diunduh 10 September 2014. 
seperti bencana alam dan kelaparan yang ekstrem tidak serta merta dikatakan sebagai pengungsi. Lebih jauh, walaupun terdapat seseorang yang mendapatkan persekusi, namun tidak berbasis pada salah satu persyaratan di atas, maka yang bersangkutan tidak bisa disebut pengungsi. Selain itu, Matthew menambahkan: "even those who face persecution on the basis of a protected ground, but who are not outside their country of citizenship, are not refugees.."

Pendapat yang berbeda tentang definisi pengungsi dipaparkan oleh Shacnove, sebagai berikut: "Desperate people from the world's poorest regions (see global poverty) and victims of natural disasters also count as refugees or something very similar to them". ${ }^{12}$ Shacnove telah membuat definisi yang luas tentang pengungsi yaitu menyertakan korban bencana alam. Dengan mengaitkan korban bencana alam tersebut sebagai pengungsi, Shacnove tidak mampu membedakan antara perlindungan yang tetap diberikan negara namun tidak mampu dilaksanakan (kasus bencana alam atau kelaparan) dengan keengganan negara untuk memberikan perlindungan bagi warga negaranya.

Senada dengan pendapat Shacknove yang mengkualifikasikan pengungsi secara luas, hukum regional tentang pengungsi, yaitu Pasal 1 ayat 2 Deklarasi Cartagena tentang Pengungsi Tahun 1984 mengatur bahwa: "The term 'refugee' shall also apply to every person who, owing to external aggression, occupation, foreign domination or events seriously disturbing public order in either part or the whole of his country of origin or nationality, is compelled to leave his place of habitual residence in order to seek refuge in another place outside his country of origin or nationality..". Perluasan definisi ini tidak lain ditujukan untuk menjawab tantangan masyarakat, bahwa persekusi tidak semata-mata dianggap sebagaimana yang terdapat dalam Konvensi Pengungsi, yaitu atas dasar ras, agama, kewarganegaraan, dan keanggotan kelompok sosial atau pendapat politik, namun terkait aspek lain yang lebih luas yaitu agresi, pendudukan dominasi asing, atau ketidakstabilan politik dalam negeri yang memaksa mereka meninggalkan negaranya. Alasan terjadinya persekusi di atas menunjukkan bahwa dimensi eksternal dapat menjadi faktor munculnya persekusi.

Memperhatikan berbagai definisi tersebut, penulis berpendapat bahwa definisi sempit tentang pengungsi lebih tepat dalam konteks merespon pengungsi global. Pendapat Shocknove yang memasukan mereka yang mengungsi karena negaranya miskin adalah kurang tepat, karena menyulitkan pembedaan antara imigran ekonomi, yaitu mereka yang mengungsi ke negara lain untuk mendapatkan penghidupan yang lebih baik dan pengungsi yang berpindah karena alasan persekusi. Adapun definisi pada kawasan Amerika Latin adalah definisi yang mengikat antar negara yang berada pada kawasan tersebut.

12 J. Seglow, "Refugees. The International Encyclopedia of Ethics", http://onlinelibrary.wiley.com/doi/ 10.1002/9781444367072. wbiee318/abstract;jsessionid=23DE59888D0248512030D619328354A2.f02t03?den iedAccessCustomisedMessage=\&userlsAuthenticated=false, diunduh 15 September 2014 . 


\section{Perlindungan Pengungsi dalam Hukum Internasional}

Sebelum berstatus sebagai pengungsi, seseorang yang memasuki wilayah suatu negara karena persekusi yang dialami di negara asalnya dianggap sebagai pencari suaka (asylum sekeer). Asylum seeker diartikan sebagai "someone who has applied for refugees status, but who has not yet received a decision on whether he/she been recognized as a refugee".$^{13}$ Terhadap negara yang telah meratifikasi Konvensi Pengungsi dan membuat mekanisme perlindungannya sendiri, maka negara yang bersangkutanlah yang menentukan apakah status sebagai pengungsi dapat diberikan atau tidak. Sebaliknya, bagi negara yang telah meratifikasi Konvensi Pengungsi namun belum membuat mekanisme perlindungannya sendiri atau negara yang belum meratifasi Konvensi Pengungsi, maka penentuan statusnya dilaksanakan oleh Kantor Perwakilan UNHCR di negara terkait.

Pengungsi yang datang ke wilayah suatu negara pada prinsipnya memiliki hak untuk tidak dikembalikan ke negara asal atau negara lain di mana jiwanya dapat terancam, atau dikenal dengan prinsip non-refoulement (Pasal 33). Prinsip nonrefoulement merupakan jantung dari Konvensi Pengungsi 1951, sehingga negara peserta konvensi tidak diperkenankan mengenyampingkan (reservation) pasal ini. Vincent Chetail menulis: "Le non refoulment est par definition une obligation d'abstention. Interdisant le renvoi du refugie sur les lieux de sa persecution et non un devoir d'agir Assurant a ce dernier un etablissement stable et durable dans le pays de refuge". ${ }^{14}$ Prinsip non-refoulement hakikatnya sebagai kewajiban untuk tidak bertindak, yaitu pelarangan mengembalikan pengungsi di atas wilayah persekusi terjadi, namun pada saat yang bersamaan bukan kewajiban negara yang menerima pengungsi untuk memastikan kediaman yang stabil dan berjangka panjang. Prinsip non-refoulement ini telah menjadi hukum kebiasaan internasional, sehingga mengikat seluruh negara di dunia tidak terkecuali mereka yang belum meratifikasi Konvensi Pengungsi ini. Sebagaimana pendapat Buergenthal: "Customary international law results from a general and consistent practice of states followed by them from a sense of legal obligation" ${ }^{15}$

Selain hak untuk tidak dikembalikan ke negara asal, pengungsi juga memiliki serangkaian hak, sebagaimana disampaikan Goodwin-Gil: ${ }^{16}$

13 UNHCR, "General Information For Asylum Seekers", http://unhcr.or.id/images-/pdf/information/general _information_for_pocs.pdf, diunduh 18 September 2014.

14 Vincent Chetail, "Le principe de non-refoulement et le statut de réfugié en droit international (The Principle of Non-Refoulement and the Refugee Status in International Law), July 19 2001. La Convention de Geneve Du 28 Juillet 1951 relative Au Statut des Refugies-50 ans après: Bilan et Perspectives," Bruylant, 2001, hlm. 3-61; Wagiman, Hukum Pengungsi Internasional, Jakarta: Sinar Grafika, 2012, hlm. 118-126.

15 Thomas Buergenthal dan Harold Maier, Public International Law, Minnesota: West Publishing Company, 2002, hlm. 22. Hal yang sama dikatakan Brownlie dengan mengutip Briely, hukum kebiasaan internasional adalah: "what is sought for is a general recognition among States of a certain practice as obligatory" dalam Ian Brownlie, Principle of Publiclinternational Law, New York: Oxford University Press, 2003, hlm. 6.

${ }^{16}$ Guy S. Goodwin-Gill, "The Convention Standards of Treatment", http://untreaty.un-.org/cod/avl/ha/prsr /prst.html, diunduh 16 September 2014. 
"...'national treatment', that is, treatment no different from that accorded to citizens, is to be granted in respect of a wide variety of matters, including the freedom to practice religion and as regards the religious education of children (article 4); the protection of artistic rights and industrial property (article 14); access to courts, legal assistance, and exemption from the requirement to give security for costs in court proceedings (article 16); rationing (article 20); identity papers (article 27), and travel documents (article 28); the grant of permission to transfer assets (article 30); and the facilitation of naturalization (article 34)..."

Negara yang telah mengikatkan diri menjadi negara peratifikasi konvensi wajib memperlakukan pengungsi sebagaimana yang diatur dalam konvensi. Hal ini tercermin dalam ketentuan pasal-pasal Konvensi Pengungsi yang memberikan serangkaian hak-hak yang luas sebagaimana disebut di atas, seperti: kebebasan menjalankan agama (Pasal 4); akses ke pengadilan dan bantuan hukum (Pasal 16); jaminan sosial (Pasal 24); dokumen perjalanan (Pasal 28); dan kemudahan untuk proses naturalisasi (Pasal 34).

Sebagaimana disebut di awal, pengungsi berharap sampai pada tujuan negara yang diinginkan. Namun, kenyataannya banyak dari mereka harus "terdampar" di negara ketiga (the third country of asylum) sebelum akhirnya menuju negara tujuan (destination country). Sebagian negara ketiga adalah negara yang telah meratifikasi Konvensi Pengungsi, namun sebagian lain adalah negara bukan peserta konvensi, seperti Indonesia. Negara tujuan pencari suaka dan pengungsi adalah negara maju peserta Konvensi Pengungsi yang sebagian dari negara tersebut memiliki program menerima pengungsi ke negara mereka secara permanen sebagai solusi jangka panjang pengungsi (resettlement).

\section{Perlakuan Terhadap Pengungsi di Negara Non-peratifikasi Konvensi}

Hukum Internasional mengenal prinsip yang menyatakan, "treaties may neither impose obligations on, nor create legal entitlements for, third states (pacta tertiis nec nocent nec prosunt)". ${ }^{17}$ Sebagaimana telah disebutkan, perjanjian internasional tidak dapat mengenakan kewajiban kepada negara ketiga. Walaupun Konvensi Pengungsi tidak mengenakan kewajiban kepada negara ketiga, bukan berarti tidak ada standar dalam memperlakukan pengungsi yang tinggal di negara ketiga tersebut. Terdapat dua pandangan dalam memperlakukan orang asing yang tinggal di suatu negara, yaitu standar internasional (international standard of treatment) dan ukuran perlakuan nasional (national standard of treatment). Standar internasional menekankan bahwa perlakuan orang asing harus berpedoman pada ukuran-ukuran internasional, sedangkan standar nasional memandang bahwa

\footnotetext{
${ }^{17}$ Sebagaimana diatur dalam Pasal 35-36 Konvensi Wina Tahun 1969 tentang Hukum Perjanjian; Antonio Cassese, International Law, Oxford: Oxford University Press, 2005, hlm. 170-171.
} 
orang asing harus diperlakukan sama dengan warga negara sesuai dengan hukum masing-masing negara. ${ }^{18}$

Terkait dengan negara ketiga tempat pengungsi tinggal, pertanyaan selanjutnya adalah langkah-langkah apa yang selayaknya dilakukan negara tersebut terhadap pengungsi setelah kedatangan mereka dan apa saja kewajiban negara tersebut terhadap pencari suaka dan pengungsi yang datang ke negaranya. Sejauh ini, tidak ada pandangan yang menyatakan apa saja yang menjadi kewajiban negara ketiga selanjutnya setelah menerima kedatangan pengungsi. Umumnya, para ahli hanya mengemukakan tiga model penyelesaian jangka panjang, yaitu: pertama, pengembalian ke negara asal pengungsi (repatriation to the country from which the refugees fled); kedua, integrasi dengan negara ketiga (integration into the country of first asylum); ketiga, penempatan di negara lain (resettlement in another country).

Solusi pertama, yaitu pengembalian ke negara asal pengungsi merupakan solusi yang paling mungkin karena mendorong integrasi kembali pengungsi dengan keluarga dan budaya mereka. Namun demikian, bukanlah pekerjaan yang mudah untuk dilaksanakan karena trauma yang dialami pengungsi sebelumnya mencegah mereka untuk kembali lagi ke negara asalnya. ${ }^{19}$ Selain itu, kondisi internal negara asal yang masih tidak memungkinkan, menambah keengganan pengungsi untuk kembali lagi ke negara asalnya.

Solusi kedua, yaitu integrasi ke negara ketiga, juga bukannya tanpa masalah. Setidaknya ada tiga faktor yang mempengaruhi kesuksesan integrasi ke negara ketiga ini, yaitu: perolehan hak-hak hukum; integrasi ekonomi yang mendorong kehidupan standar sebagaimana warga negara; serta penerimaan budaya. ${ }^{20}$ Adapun pilihan yang ketiga, penempatan ke negara lain merupakan pilihan yang paling ideal. Namun kembali, pilihan ini bukannya tanpa masalah karena, hanya sekitar 100.000 orang pengungsi yang diterima pengajuan resettlement-nya atau hanya sekitar 1 persen dari seluruh pengungsi di dunia.

Adapun bagi mereka yang belum menjangkau wilayah negara tujuan namun masih tinggal di negara ketiga sambil menunggu solusi yang tepat di antara ketiga solusi di atas, maka negara tujuan mengupayakan agar pengungsi dapat tinggal di negara ketiga tersebut dengan memberikan bantuan sebagai wujud dari pembagian beban (sharing burdens). Hal ini sebagaimana yang telah dilakukan oleh Pemerintah Indonesia dan Australia. ${ }^{21}$

\section{Pencari Suaka dan Pengungsi di Indonesia}

Sebagaimana dijelaskan sebelumnya, penanganan pengungsi tunduk terhadap

\footnotetext{
18 Yudha Bhakti Ardhiwisasra, Hukum Internasional Bunga Rampai, Bandung: PT Alumni, 2003, hIm 19-22.

19 Penny Becklumb, "Refugee Protection: The International Context", Canada Parliamentary Information and Research Service, 2008, hlm.4-18.

20 Ibid.

21 Savitri Taylor and Brynna Rafferty-Brown, Loc.cit.
} 
rezim Konvensi Pengungsi Tahun 1951. Negara-negara yang telah meratifikasi Konvensi Pengungsi berkewajiban menerapkan aturan-aturan yang ditetapkan dalam konvensi tersebut sebagaimana hukum nasional. Indonesia sebenarnya menjadikan Konvensi Pengungsi sebagai salah satu perjanjian internasional yang masuk dalam list atau daftar prioritas Rancangan Hak Asasi Manusia (RAN HAM) Pemerintah Tahun 2010-2014, sebagaimana diungkapkan dalam notulensi Direktorat Perjanjian Politik, Keamanan dan Wilayah Kementerian Luar Negeri (Kemenlu) ${ }^{22}$ berikut ini:

"..Seperti diketahui bersama, ratifikasi Konvensi 1951 telah masuk ke dalam RAN HAM. Masuknya ratifikasi Konvensi 1951 tersebut ke dalam RAN HAM cukup kontroversial. Sebelumnya, rapat inter-kementerian yang diselenggarakan oleh Kementerian Hukum dan HAM tahun 2010 telah sepakat untuk tidak memasukkan ratifikasi konvensi tersebut ke dalam RAN HAM 2011-2014 dengan berbagai alasan, antara lain adalah karena Konvensi 1951 telah ditinggalkan oleh banyak negara karena dianggap tidak lagi memadai untuk menangani isu migrasi yang semakin kompleks.."

Kebijakan di atas kertas sangat jelas menunjukan bahwa Konvensi Pengungsi menjadi salah satu konvensi yang direncanakan akan diusulkan Pemerintah untuk diratifikasi oleh DPR, tepatnya pada saat kepemimpinan Presiden Susilo Bambang Yudhoyono (SBY) yang kedua. Namun, dapat dipahami pula bahwa suara pemerintah untuk meratifikasi nampaknya bukanlah suara yang bulat karena penolakan dalam rapat antar kementerian yang dipimpin oleh Kementerian Hukum dan HAM bersepakat untuk tidak menjadikan konvensi tersebut dalam RAN HAM. Pandangan kedua ini lebih mencerminkan kondisi saat ini, karena hingga penghujung Pemerintahan SBY, belum juga diajukan Konvensi Pengungsi itu untuk segera disahkan oleh DPR.

Alasan yang dapat mewakili pertimbangan pemerintah setidaknya ditururkan oleh Ahmad dan Danardi Haryanto, Staf Bidang Hukum Direktorat Perjanjian Internasional Kementerian Luar Negeri: ${ }^{23}$

"..Ada kekhawatiran banyak pihak khususnya di pemerintahan bahwa konvensi akan memberatkan. Ada kewajiban-kewajiban didalamnya yang memberatkan. Kita belum bersedia mengikatkan diri namun kita memiliki komitmen untuk melakukan penguatan instrumen domestik selama ini tidak banyak ketentuan yang mengatur..."

Faktor ekonomi memang menjadi dasar pertimbangan dalam menentukan posisi Pemerintah Indonesia dalam masalah pengungsi. Pemerintah menganggap Indonesia belum memiliki kemampuan dalam memperlakukan pengungsi

\footnotetext{
${ }^{22}$ Fitria, “Kebijakan Pemerintah Indonesia tentang Pencari Suaka dan Pengungsi (Studi Kasus pencari Suaka dan Pengungsi Etnis Rohignya di Indonesia)", Penelitian tidak terpublikasi, disponsori oleh UIN Syarif Hidayatullah Jakarta, 2013, hlm.31.

${ }^{23} \mathrm{Ibid}, \mathrm{hlm} .32$.
} 
sebagaimana diamanatkan konvensi. Apabila kita merujuk kembali kepada ketentuan konvensi yang telah disebutkan sebelumnya, diatur bahwa pemerintah memiliki serangkaian tanggung jawab guna menjamin keberlangsungan hidup pengungsi di negaranya. Kewajiban-kewajiban yang dibebankan kepada negara memang berdimensi luas, bukan saja aspek hak ekonomi dan sosial pengungsi, namun juga termasuk hak sipil dan politik.

Posisi pemerintah sebagaimana tercermin di atas sejalan dengan sikap sebagian besar partai politik saat ini yang melihat pencari suaka dan pengungsi sebagai beban yang akan memberatkan perekonomian negara. Hal tersebut setidaknya dapat ditelusuri dalam proses pembahasan Rancangan Undang-Undang (RUU) tentang Keimigrasian, hampir semua Fraksi DPR RI sepakat untuk tidak memasukkan ketentuan pencari suaka dan pengungsi dalam UU Keimigrasian yang dibuat. Sebagaimana telah diketahui, UU Keimigrasian mengatur tentang lalu lintas manusia, sehingga sangat dimungkinkan diatur pula mengenai pencari suaka dan pengungsi dalam peraturan ini. Argumen yang berkembang saat itu adalah apabila Indonesia memasukkan ketentuan pencari suaka dan pengungsi ini, berarti Indonesia mengakui keberadaan dan status mereka.

Dasar argumen penolakan sebagian besar fraksi tersebut sebenarnya kurang tepat, karena sebenarnya pengungsi (internasional) telah diakui dalam ketentuan perundang-undangan Indonesia, khususnya dalam Undang-Undang Nomor 37 tahun 1999 tentang Hubungan Luar Negeri Pasal 27 ayat (1): "Presiden menetapkan kebijakan masalah pengungsi dari luar negeri dengan memperhatikan pertimbangan Menteri". Namun sayangnya, kebijakan Presiden hingga saat ini belum juga dirumuskan.

\section{Pengungsi Dalam Peraturan Perundang-Undangan di Indonesia}

Sebagaimana disebutkan di atas, apabila menelusuri lebih jauh tentang konstitusi dan peraturan perundang-undangan yang ada, sebenarnya ketentuan pencari suaka dan pengungsi bukannya tidak diatur sama sekali, berikut sekilas mengenai ketentuan tersebut:

\section{Tabel 1}

\section{Pengaturan tentang Pesuaka dan Pengungsi}

\begin{tabular}{|c|c|c|}
\hline No & $\begin{array}{c}\text { UUD dan Peraturan Perundang- } \\
\text { Undangan }\end{array}$ & Rumusan \\
\hline 1. & UUD 1945 Pasal 28 G & $\begin{array}{l}\text { Setiap Orang berhak untuk bebas dari } \\
\text { penyiksaan atau perlakuan yang merendahkan } \\
\text { derajat martabat manusia dan berhak } \\
\text { memperoleh suaka politik dari negara lain. }\end{array}$ \\
\hline
\end{tabular}




\begin{tabular}{|c|c|c|}
\hline 2. & Tap MPR No. XVII/MPR/1998 & $\begin{array}{l}\text { TAP MPR ini terdiri dari tiga bagian, salah satu } \\
\text { bagiannya mengakui keberadaan Deklarasi } \\
\text { Universal Hak Asasi Manusia (DUHAM), yang } \\
\text { mana dalam salah satu pasalnya, yaitu pasal } \\
24 \text { mengatur bahwa: "setiap orang berhak } \\
\text { mencari suaka untuk memperoleh } \\
\text { perlindungan politik dari negara lain." }\end{array}$ \\
\hline 3. & $\begin{array}{l}\text { Undang-Undang Nomor } 12 \text { Tahun } \\
2005 \text { tentang Pengesahan Konvensi } \\
\text { Hak Sipil dan Politik } \\
\text { (UU Hak Sipol) }\end{array}$ & $\begin{array}{l}\text { Pasal } 12 \text { ayat (2): setiap orang bebas untuk } \\
\text { meninggakan negara manapun termasuk } \\
\text { negaranya. } \\
\text { Pasal 7: Setiap orang tidak boleh dijadikan } \\
\text { sasaran penyiksaan atau hukuman yang tidak } \\
\text { manusiawi. }\end{array}$ \\
\hline 4. & $\begin{array}{l}\text { Undang-Undang Nomor } 5 \text { Tahun } \\
1998 \text { tentang Pengesahan Konvensi } \\
\text { Menentang Penyiksaan dan } \\
\text { Perlakuan Lain yang Kejam, Tidak } \\
\text { Manusiawi, atau Merendahkan } \\
\text { Martabat Manusia } \\
\text { (UU CAT) }\end{array}$ & $\begin{array}{l}\text { Pasal 3: Tidak boleh ada negara yang menolak, } \\
\text { mengembalikan atau mengekstradisi } \\
\text { seseorang ke negara yang mana terdapat } \\
\text { keyakinan/alasan yang kuat bahwa dia akan } \\
\text { berbahaya karena menjadi sasaran } \\
\text { penyiksaan. }\end{array}$ \\
\hline 5. & $\begin{array}{l}\text { Undang-Undang Nomor } 37 \text { Tahun } \\
1999 \text { tentang Hubungan Luar Negeri } \\
\text { (UU Hublu) }\end{array}$ & $\begin{array}{l}\text { Pasal } 25 \text { ayat (1): Kewenangan pemberian } \\
\text { suaka kepada orang asing berada di tangan } \\
\text { Presiden dengan memperhatikan } \\
\text { pertimbangan Menteri. } \\
\text { Pasal } 27 \text { ayat (1): Presiden menetapkan } \\
\text { kebijakan masalah pengungsi dari luar negeri } \\
\text { dengan memperhatikan pertimbangan } \\
\text { Menteri. }\end{array}$ \\
\hline 6. & $\begin{array}{l}\text { UU No } 6 \text { Tahun } 2011 \text { tentang } \\
\text { Keimigrasian (UU Keimigrasian) }\end{array}$ & $\begin{array}{l}\text { Pasal 86: } \\
\text { Ketentuan tindakan administratif keimigrasian } \\
\text { tidak diberlakukan terhadap korban } \\
\text { perdagangan orang dan penyelundupan } \\
\text { manusia. } \\
\text { Pasal 87: } \\
\text { (1) Korban perdagangan orang dan } \\
\text { penyelundupan manusia yang berada di } \\
\text { wilayah Indonesia ditempatkan di dalam } \\
\text { Rumah Detensi Imigrasi (Rudenim) atau di } \\
\text { tempat lain yang ditentukan. } \\
\text { (2) Korban perdagangan orang dan } \\
\text { penyelundupan manusia sebagaimana } \\
\text { dimaksud pada ayat (1) mendapatkan } \\
\text { perlakuan khusus yang berbeda dengan Deteni } \\
\text { pada umumnya. } \\
\text { Pasal } 88 \text { : } \\
\text { Menteri atau pejabat imigrasi yang ditunjuk } \\
\text { mengupayakan agar korban perdagangan } \\
\text { orang dan penyelundupan manusia yang } \\
\text { berkewarganegaraan asing segera }\end{array}$ \\
\hline
\end{tabular}




\begin{tabular}{|c|l|l|}
\hline & & $\begin{array}{l}\text { dikembalikan ke negara asal mereka dan } \\
\text { diberikan surat perjalanan apabila mereka } \\
\text { tidak memilikinya. }\end{array}$ \\
\hline 7. & $\begin{array}{l}\text { Peraturan Dirjen Imigrasi Nomor: } \\
\text { IMI-1489.UM.08.05 Tahun 2010 } \\
\text { tentang Penanganan Imigran llegal }\end{array}$ & $\begin{array}{l}\text { Pada bagian menimbang secara jelas } \\
\text { disebutkan bahwa latar belakang diterbitkan } \\
\text { peraturan Dirjen Imigrasi adalah ..bahwa } \\
\text { dalam perkembangannya kedatangan dan } \\
\text { keberadaan orang asing sebagai imigran ilegal } \\
\text { yang kemudian menyatakan dirinya sebagai } \\
\text { pencari suaka dan pengungsi.. } \\
\text { Isi peraturan Dirjen menyangkut penanganan } \\
\text { pencari suaka dan pengungsi. }\end{array}$ \\
\hline 8. & $\begin{array}{l}\text { Pasal 206, 221 dan 223 Peraturan } \\
\text { Pemerintah Nomor 31 Tahun 2013 } \\
\text { tentang Keimigrasian }\end{array}$ & $\begin{array}{l}\text { Ketentuan-ketentuan yang ada pada PP } \\
\text { mengatur tentang pendetensian pengungsi } \\
\text { (imigran ilegal) hingga 10 tahun. PP tersebut } \\
\text { mengatur bahwa, setelah 10 tahun } \\
\text { pendetensian mereka dapat dikeluarkan } \\
\text { dengan kewajiban melaporkan selama enam } \\
\text { bulan sekali dan kewajiban melaporkan ke } \\
\text { kantor imigrasi apabila ada perubahan status } \\
\text { dan pekerjaan mereka. }\end{array}$ \\
\hline
\end{tabular}

Berdasarkan tabel di atas, ada beberapa hal yang dapat dikaji. Pertama, walaupun tidak ada pengaturan tentang pencari suaka dan pengungsi yang komprehensif, peraturan perundang-undaangan di Indonesia membuka ruang bagi kehadiran pencari suaka dan pengungsi di Indonesia. Bahkan, kata pengungsi muncul dalam UU Hublu yang menegaskan "pengungsi dari luar negeri" berbeda dengan pengungsi dalam negeri (internally displaced persons-IDP). Namun sayangnya, kata pengungsi belum didefinisikan dalam UU ini. ${ }^{24}$ Sebenarnya UU Hublu mengamanatkan dibentuknya Keputusan Presiden (Kepres, sekarang Peraturan Presiden), namun setelah lebih dari tiga belas tahun berselang, tidak ada inisiatif dari presiden untuk merumuskan peraturan tersebut agar ketentuan ini menjadi lebih jelas.

Kedua, berbagai peraturan di atas menguatkan bahwa prinsip non-refoulement menjadi komitmen yang secara hukum diakui Pemerintah Indonesia, sebagaimana juga termaktub dalam Convention Againts Torture (CAT) yang telah diratifikasi Indonesia. Ketiga, instrumen hukum terkini yaitu UU Keimigrasian, sayangnya tidak menyinggung pengungsi secara eksplisit dalam ketentuannya. Padahal UU Keimigrasian dapat mengatur tentang pengungsi dalam substansi materinya. ${ }^{25}$

${ }^{24}$ Fitria, "Penanganan Pencari Suaka dan Pengungsi di Indonesia: Dilema Peraturan Setengah Hati", dalam Heru Susetyo (et.al), Rohingya Suara Etnis yang Tidak Boleh Bersuara, Jakarta: PAHAM dan PIARA, 2013, hlm. 109-114.

${ }^{25}$ Fahri Hamzah dalam artikelnya menunjukkan harapan pengaturan tentang pengungsi, namun harapan tersebut tidak bisa terealisasi sehingga hanya menempatkan pengungsi sebagai korban perdagangan manusia yang tidak boleh dideportasi dan dihukum dan pemerintah harus berkoordinasi dalam penanganannya bersama UNHCR 
UU Keimigrasian menggunakan istilah korban penyeludupan orang dan perdagangan manusia karena sebagian besar pencari suaka dan pengungsi adalah sekaligus sebagai korban penyelundupan dan perdagangan manusia. Berkaitan dengan hal tersebut, Enny Suprapto menggarisbawahi bahwa: "sudah tentu Pasal 88 seharusnya hanya dapat diberlakukan terhadap korban perdagangan orang yang murni artinya yang bukan sekaligus juga pencari suaka atau pengungsi". ${ }^{26}$ Pendapat Enny Suprapto tersebut merupakan jalan keluar terhadap kemungkinan terjadinya pengusiran atau pengembalian paksa "korban perdagangan orang" yang sekaligus juga "pencari suaka" atau "pengungsi" dapat dilaksanakan. Harus menjadi catatan penting bahwa pelaksanaan ketentuan Pasal 88 tentunya membutuhkan koordinasi dan pemahaman bagi para petugas terkait pelaksanaan di lapangan, karena apabila tidak dipahami secara tepat, maka komitmen Indonesia untuk mengikatkan diri kepada hukum kebiasaan internasional non-refoulement menjadi tidak dapat dilaksanakan.

\section{Perlindungan Hukum Terhadap Pengungsi: Praktik Indonesia}

Sebagai negara yang belum meratifikasi Konvensi Pengungsi, Indonesia menjalin kerja sama dengan pihak lain dalam menangani pencari suaka dan pengungsi yang masuk ke wilayahnya, yaitu Pemerintah Australia, UNHCR, dan IOM. Mengenai hal ini Taylor menulis: "Australia has also attempted to improve the acces to protection of asylum sekeers in Indonesia trough an arrangement with the Indonesian government and the International Organization for Migration (IOM) under so-called Regional Cooperation Arrangement (RCA), Indonesian authorities intercept irregular migrants and refer those they determine to have been headed toward Australia or New Zealand to IOM for case management and care. IOM in turn refers those who indicate that they wish to make asylum claims to the UNHCR. IOM's RCA activities are funded by Australia". ${ }^{27}$

Tergambar bahwa Indonesia telah berbagi peran dalam menangani kasus pencari suaka dan pengungsi yang masuk ke wilayah Indonesia. UNHCR menjadi pihak yang memproses klaim pencari suaka mendapatkan status pengungsi sekaligus juga mencari negara yang memiliki program resettlement sebagai solusi jangka panjang pengungsi. Adapun IOM memfasilitasi pencari suaka yang memiliki keinginan untuk kembali ke negara asalnya ketika kondisi negara asalnya memungkinkan dan menyiapkan dukungan logistik terhadap pencari suaka dan pengungsi yang didetensi ataupun yang tinggal di community house di bawah pengawasannya.

dan IOM, dalam Fahri Hamzah, "Immigration Law Moves The Wall into Gateway", http://www.thejakarta post.com/news/2011/04/14/immigration-law-moves-\%E2\%80\%98-wall\%E2\%80\%99-\%E2\%80\%98gateway\%E2\%80\%99.html.

${ }^{26}$ Fitria, “Konsep Pencari Suaka dan Pengungsi Menurut Undang-Undang No 5 Tahun 2012 tentang Keimigrasian”, Penelitian tidak terpublikasi, disponsori oleh UIN Syarif Hidayatullah Jakarta, hlm. 30.

27 Savitri Taylor dan Brynna Rafferty-Brown, Loc.cit.; Australia telah membiayai IOM dan UNHCR. Sebagai contoh, pada tahun 2000 Australia telah mendanai 763.870\$ untuk UNHCR dan sebesar 702.000\$ pada tahun 20082009. 
Pengungsi yang masuk ke wilayah Indonesia menyebar di berbagai tempat. Data keberadaan pengungsi di Indonesia tahun 2013 lalu menunjukan bahwa terdapat 5.761 pengungsi yang tinggal secara mandiri (sebagian besar tinggal di Cisarua), 2381 tinggal di community house Organisasi Migrasi Internasional (IOM), dan 1921 orang ditahan di Rumah Detensi Imigrasi (Rudenim). ${ }^{28}$ Namun, berdasarkan pengamatan Penulis, terdapat pula pencari suaka dan pengungsi yang tinggal secara mandiri, baik mengontrak maupun menumpang ke sesama pencari suaka dan pengungsi. Terhadap pencari suaka dan pengungsi yang ditahan di Rudenim ini, UNHCR berpendapat:

"UNHCR continues to pursue its advocacy for the release of POCS from detention (refugees/asylum-seekers) held in detention centres. While, the Directorate General of Immigration responded to this request by releasing some refugees and families to IOM community housing schemes, there is no uniform approach throughout the country leaving POCS in a difficult situation as they face long periods of detention while waiting for a durable solution, of particular concern is the detention of minors and persons with specifics needs."

Menempatkan pencari suaka dan pengungsi dalam Rudenim adalah sesuatu yang melanggar hukum internasional, karena prinsipnya keberadaan mereka dalam Rudenim mengurangi hak-hak yang sejatinya dapat dimiliki. Sebagaimana diketahui pula, pencari suaka dan pengungsi sekalipun masuk ke wilayah Indonesia dengan dokumen yang tidak sah atau tanpa dokumen haruslah mendapatkan perbedaan perlakuan dengan mereka yang merupakan imigran ilegal lainnya. Imigran ilegal selain pencari suaka dan pengungsi tidak memiliki dasar yang kuat untuk meninggalkan negara asalnya melainkan semata-mata mencari kehidupan yang lebih baik, oleh karenanya deportasi imigran ilegal ke negara asalnya atau bahkan penempatan imigran ilegal di Rudenim dapat diterima hukum internasional. Sebaliknya, pencari suaka dan pengungsi adalah kategori lain yang harus mendapatkan perlindungan internasional, sehingga menempati mereka di Rudenim merupakan bentuk penurunan nilai martabat mereka.

Keberadaan pengungsi di Rudenim jelas menimbulkan masalah. Walaupun Rudenim bukan penjara, namun dalam praktiknya Rudenim mirip dengan penjara. ${ }^{29}$ Deteni menempati sel/tempat tinggal yang lebih manusiawi dibandingkan penjara, yaitu ruang sekitar 3x4 meter yang dihuni sekitar 3-4 orang. Saat ini terdapat 221 orang yang ditahan, dengan 10 diantaranya masih anak-anak. Karena kapasitas yang tidak memadai, 6 orang ditahan harus tinggal di aula.

\footnotetext{
28 Deputi IV Kementerian Politik dan Keamanan Nasional, “Kebijakan Indonesia Tentang Imigran Ilegal terkait dengan Kedaulatan dan Tanggung Jawab Negara," Makalah dalam Seminar Djoko Soetono Research Center FH UI, 5 Desember 2013.

${ }^{29}$ Sebagaimana penelusuran penulis di Rudenim Kali Deres Jakarta tanggal 17 November 2014.
} 
Sebagaimana yang disebutkan sebelumnya, pencari suaka dan pengungsi yang ditahan dalam Rudenim bukan saja laki-laki dewasa namun juga termasuk anakanak dan wanita. ${ }^{30}$ Walaupun mereka disatukan dengan keluarga mereka, aktivitas yang dapat dilakukan dalam ruangan sangat terbatas. Sebagai contoh, keluarga pengungsi Palestina telah menempati Rudenim selama satu tahun dengan anak mereka yang baru berumur dua tahun. Kehadiran anak dalam Rudenim menyisakan pertanyaan tentang hak atas anak-anak tersebut, seperti misalnya hak atas pendidikan. Selain keluarga pengungsi Palestina, berdasarkan pengamatan penulis, ada juga keluarga Afganistan yang salah satu anak mereka telah mencapai usia sekolah, yaitu 6 tahun. Mengenai hal tersebut, Rudenim Kali Deres, melalui fasilitasi IOM, bekerjasama dengan Pusat Krisis Psikologi UI menyelenggarakan pengajaran bagi anak-anak pengungsi yang dilakukan setiap seminggu sekali. Sayangnya, keterbatasan anggaran yang dimiliki IOM membuat program ini hanya bertahan beberapa bulan. ${ }^{31}$

Di sisi lain, pencari suaka dan pengungsi yang berintegrasi dengan masyarakat menurut pandangan pemerintah tidak juga berjalan lancar. Adapun mengenai mereka yang tinggal dengan penduduk setempat yang sebagian besar terkonsentrasi di Cisarua, Bogor juga memunculkan masalah. Masalah tersebut diantaranya gangguan Kamtibmas, fenomena kawin kontrak, serta tindakan kriminalitas seperti narkoba dan terorisme. ${ }^{32}$ Pemerintah memiliki kewenangan untuk memproses hukum pencari suaka dan pengungsi yang melakukan tindak pidana untuk dijadikan pelajaran bagi pencari suaka dan pengungsi lain agar tidak melakukan hal serupa.

Selain di Bogor, sebagian pencari suaka dan pengungsi juga menempati rumah kontrakan di Jalan Kebon Sirih dekat Kantor Perwakilan UNHCR. Berdasarkan pengamatan dan wawancara penulis dengan beberapa pencari suaka dan pengungsi, ${ }^{33}$ ditemukan fakta bahwa keberadaan mereka baik pencari suaka dan pengungsi belum mendapatkan dukungan apapun, baik dari IOM maupun UNHCR. Sebagian dari mereka dapat melanjutkan hidup dengan mendapatkan dukungan keuangan dari keluarga asal pengungsi melalui transfer uang secara rutin, namun sebagian besar yang lain bertahan hidup dengan menumpang tinggal ke sesama pencari suaka dan pengungsi. Sebagian dari mereka baru sampai di Indonesia sekitar dua bulan, namun sebagian yang lain sudah mencapai lebih dari setahun. Mereka tetap bersabar dengan keterbatasan yang ada karena besarnya harapan akan hidup yang lebih baik di kemudian hari.

30 Ibid.

31 Wawancara dengan Sukarelawan Pusat Krisis Psikologi UI pada tanggal 17 November 2014.

32 Deputi IV Bidang Kamnas Kemenpolkan, Loc.cit.

${ }^{33}$ Wawancara dengan pencari suaka dan pengungsi di kawasan Kebun Sirih tanggal 27 Oktober 2014. Penulis melakukan wawancara dengan Muhammad Abdul Azis (Somalia), Rashad Fayaz (Afganistan), Muhammad (Syria), Ismed Baha (Sudan), Ayan Ilmi (Somalia) dan Ali (Iran). 
Penulis juga menemukan pengungsi yang dibiayai oleh lembaga kemanusiaan, yaitu Dompet Dhuafa. ${ }^{34}$ Sebelumnya, Dompet Dhuafa mendapatkan informasi dari LBH Jakarta bahwa terdapat pengungsi asal Rohingya yang tinggal di Mesjid Sunda Kelapa pada tahun 2013 lalu. Pengungsi yang berjumlah 33 orang dan terdiri dari 3 keluarga ini mendapatkan bantuan sejumlah dua juta rupiah untuk masing-masing keluarganya. Untuk melaksanakan hal tersebut, Dompet Dhuafa mencarikan tempat mereka mengontrak di sekitar Depok, Jawa Barat dengan menggandeng sukarelawan dari Universitas Indonesia (UI) yang memberikan pengajaran bagi anak-anak Rohingya selama tiga kali dalam seminggu. Adapun mengenai pengurusan status pengungsi, Dompet Dhuafa melakukan kerjasama dengan LBH Jakarta. Hampir dua tahun berselang, Dompet Dhuafa tidak lagi mendapati kabar Pengungsi Rohingya tersebut. Diketahui bahwa mereka telah berpindah menuju Christmas Island, Australia.

Berdasarkan informasi yang didapat penulis melalui staf UNHCR dan staf Dirjen Keimigrasian Kementerian Hukum dan HAM, terdapat pencari suaka dan pengungsi yang memiliki latar belakang pendidikan yang bagus, bahkan ada di antara mereka yang telah berpendidikan doktor. Pendidikan yang memadai tersebut tidak akan dapat meningkatkan taraf hidup mereka karena hak mereka untuk bekerja tidak diatur oleh Pemerintah Indonesia. Sebenarnya hak untuk bekerja ini secara implisit telah diakui dalam Peraturan Pemerintah Nomor 31 Tahun 2013 tentang Keimigrasian, namun masih diperlukan pengaturan yang tegas mencakup pengaturan mengenai koordinasi dengan instansi lain seperti Kementerian Tenaga Kerja dan Transmigrasi terkait permasalahan ini.

Selain masalah hak untuk bekerja, sudah menjadi kebutuhan lumrah seorang manusia untuk melanjutkan keturunan melalui cara yang sah, yaitu perkawinan. Tanpa payung hukum, sebuah perkawinan yang hanya disahkan menurut hukum Islam akan memunculkan permasalahan selanjutnya, yaitu perlindungan terhadap perempuan yang dinikahi dan perlindungan hukum terhadap anak-anak yang lahir dalam pernikahan tersebut.

Kehadiran anak hasil pernikahan antara pencari suaka dan pengungsi dan perempuan warga negara Indonesia ini menunjukkan integrasi yang lebih kuat antara pencari suaka dan pengungsi dengan Indonesia, karena Indonesia sudah menjadi bagian dari kehidupan mereka. Terkait hal tersebut, tentunya tidak mudah pula bagi UNHCR untuk mengajukan mereka menjadi peserta penempatan di negara ketiga, karena UNHCR pasti akan mengajukan orang-orang dengan kondisi yang lebih paling memungkinkan. Sebagaimana paparan sebelumnya, UNHCR hanya memproses 1 persen dari seluruh pengungsi di dunia yang mengikuti program resettlement ini.

\footnotetext{
${ }^{34}$ Wawancara dengan Rama Adi Wibowo, staff Social Development Division Dompet Dhuafa, pada hari Rabu, Tanggal 17 November 2014.
} 
Tabel 2

Resettlement Pengungsi pada Negara Ketiga (1 Januari 2012-31 Januari 2012)

\begin{tabular}{|l|r|r|}
\hline Negara & Pengajuan & Penerimaan \\
\hline Australia & 911 & 532 \\
\hline Kanada & 13 & 7 \\
\hline Amerika & 28 & 22 \\
\hline New Zealand & 13 & 13 \\
\hline Norwegia & 3 & 3 \\
\hline
\end{tabular}

Tidak semua orang diajukan untuk menjalani program ini diterima negara. Sebagaimana UNHCR mengatur: "Resettlement is not a right and there is no obligation on States to accept refugees for resettlement". ${ }^{35}$ Tidaklah mudah bagi negara mengikuti program ini karena harus mampu memberikan perlindungan, bukan hanya perlindungan hukum namun juga perlindungan fisik, yang diantaranya adalah akses untuk mendapatkan hak sipil, politik, ekonomi, dan budaya sebagaimana yang dimiliki mereka yang berkewarganegaraan. ${ }^{36}$ Adapun perlindungan hukum yang diberikan adalah kesempatan bagi pengungsi untuk melakukan naturalisasi sehingga mendapatkan kewarganegaraan negara di mana dia ditempatkan.

Oleh karena itu, pada tahun 2012 hanya 26 negara $^{37}$ atau sedikit saja dari negara di dunia yang ikut berkontribusi dalam program resettlement yang diselenggarakan oleh UNHCR. Dari negara-negara di dunia, Amerika Serikat merupakan negara dengan tingkat resettlement tertinggi. Selain itu Australia, Kanada, dan negara-negara Skandinavia menempati posisi terbanyak setiap tahunnya. ${ }^{38}$

Berdasarkan data di atas, terlihat bahwa resettlement oleh UNHCR lebih banyak menuju ke Australia (2012). Hal ini tentu saja tidak lepas dari kuota yang disediakan oleh Australia, dengan salah satu pertimbangannya adalah secara geografis dekat dengan Indonesia. Namun saat ini berlaku kebijakan terbaru Australia, (protection elsewhere policy) ${ }^{39}$ yang tidak menerima siapapun untuk ditempatkan di Australia.

35 UNHCR, "Frequently asked questions about Resettlement", http://www.unhcr.org/4ac0873d6.pdf.

36 Ibid.

37 Ibid.

38 UNHCR, "Resettlement", http://www.unhcr.org/pages/4a16b1676.html.

39 Australia telah menandatangani Perjanjian Transfer Pengungsi dengan Pemerintah Kamboja untuk mengalihkan pemukiman pengungsi dari Kepulauan Nauru menuju Kamboja, dalam BBC, "Australia and Cambodia Sign Refugee Resettlement Deal", http://www.bbc.com/news/world-asia-29373198; Human Rights, "Transfer Asylum Seeker Third Countries", https://www.humanrights.gov.au/transfer-asylum-seekers-third-countries, diakses pada 2 October 2014. Protection elsewhere policy ini dimaknai Foster sebagai: "a situation in which a state or agency acts on the basis that the protection needs of a refugee should be considered or addressed somewhere other than in the territory of the state where the refugee has sought, or intends to seek, protection", 
Kebijakan ini kedepannya akan memberikan implikasi besar bagi Indonesia. Sebagaimana data di atas, Australia menjadi penyumbang terbesar (95\%) program penempatan kembali pengungsi ke negaranya pada tahun 2012 lalu.

Paparan di atas semakin menguatkan bahwa integrasi dengan masyarakat Indonesia menjadi pilihan yang paling mungkin dapat diterima bagi para pengungsi. Kondisi geopolitik yang masih labil di negara asal mayoritas pencari suaka dan pengungsi di Indonesia menunjukkan bahwa program pengembalian atau repatriasi pencari suaka dan pengungsi ke negara asal sulit untuk dilakukan. Untuk itu, kedepannya perlu pengaturan yang lebih komprehensif tentang pencari suaka dan pengungsi di Indonesia agar mereka dapat hidup sejatinya sebagai manusia.

\section{Penutup}

Pengungsi adalah kategori orang asing yang perlu mendapatkan perlindungan hukum secara khusus, karena adanya ancaman penuntutan yang dialami di negara asalnya. Konvensi Pengungsi memberikan serangkaian kewajiban bagi negara peratifikasi konvensi untuk menjamin bahwa pengungsi mendapatkan akses standar hidup minimal di negara peratifikasi tersebut. Diakuinya prinsip nonrefoulement sebagai hukum kebiasaan internasional menguatkan bahwa masalah pencari suaka dan pengungsi bukan saja menjadi masalah negara peratifikasi namun juga negara non-peratifikasi konvensi. Terhadap negara non-peratifikasi, terdapat tiga skema penanganan yang berlaku secara internasional, yaitu: pertama, pemulangan ke negara asal apabila memungkinkan (repatriation); kedua, integrasi dengan warga setempat (integration); dan ketiga, penempatan kembali ke negara lain (resettlement).

Faktor ekonomi merupakan alasan utama Indonesia yang juga belum meratifikasi Konvensi Pengungsi hingga saat ini. Peraturan nasional yang ada telah menyebutkan pencari suaka dan pengungsi, namun sesungguhnya belum ada pengaturan dalam satu instrumen yang memadai. Ketiadaan pengaturan ini menyebabkan tidak adanya standar penanganan pencari suaka dan pengungsi yang baku. Nampaknya, pemerintah dan DPR merasa dengan melibatkan organisasi internasional, seperti IOM dan UNHCR, upaya menanggulangi masalah pengungsi dan pencari suaka dinilai sudah memadai. Padahal, masih terdapat kendala di lapangan yang tidak terhindarkan. Pertama, pemerintah tidak mampu mengontrol sepenuhnya kehadiran pencari suaka dan pengungsi di Indonesia. Sebagian pencari suaka dan pengungsi saat ini ditempatkan di Rudenim, sebagian lain dari mereka berada di bawah supervisi community house IOM, sebagian lain mengontrak bersama sesama pencari suaka dan pengungsi, dan sebagian lain berbaur bersama masyarakat. Kedua, Direktorat Keimigrasian Kementerian Hukum dan HAM 
merupakan institusi utama yang menangani kehadiran pencari suaka dan pengungsi, namun kenyataannya permasalahan pencari suaka dan pengungsi sangat kompleks sehingga memerlukan keterlibatan lintas instansi seperti Kemenlu, Kemenpolkam, Kementerian Perempuan dan Anak, Kementerian Pendidikan, dan Kementerian Tenaga Kerja. Ketiga, kondisi politik dan keamanaan global menunjukkan, bahwa pilihan repatriasi dan resettlement menjadi sulit dilakukan sehingga integrasi dengan masyarakat adalah pilihan yang tidak bisa dihindarkan. Integrasi pengungsi ke masyarakat membutuhkan keterlibatan berbagai pihak seperti masyarakat, Lembaga Swadaya Masyarakat (LSM), dan pelaku usaha.

\section{Daftar Pustaka}

\section{Buku}

Achmad Romsan, (et.al), Pengantar Hukum Pengungsi Internasional: Hukum Internasional dan Prinsip-Prinsip Perlindungan Internasional, UNHCR, Bandung, 2003.

Atik Krustiyati, Penanganan Pengungsi di Indonesia, Brilian Internasional, Surabaya, 2010.

Brownlie, Ian, Principle of Public International Law, Oxford University Press, New York, 2003.

Buergenthal, Thomas dan Maier Harold, Public International Law, West Publishing Company, Minnesota, 2002.

Cassese, Antonio, International Law, Oxford University Press, Oxford, 2005.

Chetail, Vincent dan Flauss Jean-François, Le Principe de Non-Refoulement et le

Statut de Réfugié en Droit international, Bruylant, Jenewa, 2001.

Heru Susetyo, (et.al), Rohingya Suara Etnis yang Tidak Boleh Bersuara, PAHAM dan PIARA, Jakarta, 2013.

Jastram, Kate dan Achiron Marlyn, Perlindungan Pengungsi, Penerjemah Enny

Suprapto dan Rama Slamet, Komisariat Tinggi Perserikatan Bangsa-Bangsa dan

Uni Antar Parlemen, Jakarta, 2004.

Wagiman, Hukum Pengungsi Internasional, Sinar Grafika, Jakarta, 2012.

Yudha Bhakti Ardhiwisasra, Hukum Internasional Bunga Rampai, PT Alumni, Bandung, 2003.

\section{Dokumen Lain}

BBC, "Australia and Cambodia Sign Refugee Resettlement Deal", http://www.bbc .com/news/world-asia-29373198.

Becklumb, Penny, "Refugee Protection: The International Context, Background Paper", Canada Parliamentary Information and Research Service, Oktober.

Deputi IV Kementerian Politik dan Keamanan Nasional, "Kebijakan Indonesia Tentang Imigran Ilegal terkait Dengan Kedaulatan dan Tanggung Jawab Negara", 
Makalah dalam Seminar diselenggarakan oleh Djoko Soetono Research Center FHUI, 5 Desember 2013.

Enny Soeprapto, "Promotion of Refugee in Indonesia", Jurnal Hukum International, Volume 2, Nomor 1, Oktober 2004.

Fitria, "Kebijakan Pemerintah Indonesia tentang Pencari Suaka dan Pengungsi (Studi Kasus Pencari Suaka dan Pengungsi Etnis Rohignya di Indonesia)", Penelitian tidak terpublikasi disponsori oleh UIN Syarif Hidayatullah Jakarta, 2013.

Fitria, "Konsep Pencari Suaka dan Pengungsi Menurut Undang-Undang Nomor 5 Tahun 2012 Tentang Keimigrasian", Penelitian tidak terpublikasi yang disponsori oleh UIN Syarif Hidayatullah Jakarta.

Goodwin-Gill, Guy S., "The Convention of Standards Treatment", http://untreaty.un.org/cod/avl/ha/prsr/prsr.html.

Hamzah, Fahri, "Immigration Law Moves the Wall into Gateway", http://www.the jakartapost.com/news/2011/04/14/immigration-law-moves-\%E2\%80\%98wall\%E2\%80\%99-\%E2\%80\%98-gateway\%E2\%80\%99.html

Harley, Mathew, "Refugee Protection", https://digitalcollections.anu.edu.au/ bitstream/1885/11662/1/Mathew\%20\%26\%20Harley\%20Refugee\%20protec tion\%202014.pdf.

Human Rights, "Transfer Asylum Seeker Third Countries", https://www.human rights.gov.au/transfer-asylum-seekers-third-countries

Jaquemet Stephane, "Mandat dan Fungsi dari Komisariat Tinggi Perserikatan Bangsa-Bangsa (UNHCR)", Jurnal Hukum Internasional Fakultas Hukum Universitas Indonesia, Volume 2, Nomor 1, Oktober 2004.

Michelle, Foster, "Responsibility Sharing or Shifting? Safe Third Countries and International Law", Refugee Jurnal, Volume 25, Nomor 2, 2008.

Penelope, Mathew dan Harley Tristan, "Refugees Protection and Regional Cooperation In Souteast Asia, A Field Work Research", Australian National University (ANU), Maret 2014.

Savitri, Taylor dan Brynna Rafferty-Brown, "Difficult Journeys: Accesing Refugee Protection in Indonesia", Monash University Law Review, Volume 36, Nomor 3, 2010.

Portal Nasional Republik Indonesia, "Geografi Indonesia", http://www.indonesia .go.id/in/sekilas-indonesia/geografi-indonesia.

"Frequently Asked Questions About Resettlement", http://www.unhcr .org/4ac0873d6.pdf.

"General Information For Asylum Seekers", http://unhcr.or.id /images/pdf/information/general_information_for_pocs.pdf.

, "Operation fact sheet Indonesia", http://www.unhcr.or.id /images/pdf/publications/operational_fact_sheet_indonesia_final.pdf. 
, "Resettlement", http://www.unhcr.org/pages/4a16b1676.html.

"States Party to The 1951 Convention relating to the Status Refugees and the 1967

Protocol", http://www.unhcr.org/3b73b0d63.html, diunduh 10 September 2014. , "Who We Help", http://unhcr.or.id/en/who-we-help/refugees.

Wawancara dengan Pencari Suaka dan Pengungsi di kawasan Kebun Sirih:

Muhammad Abdul Azis (Somalia), Rashad Fayaz (Afganistan), Muhammad (Syria), Ismed baha (Sudan), Ayan Ilmi (Somalia) dan Ali (Iran).

Wawancara dengan Rama Adi Wibowo, staf Social Development Division Dompet Dhuafa

Wawancara Sukarelawan Pusat Krisis Psikologi UI yang bekerjasama dengan IOM dalam menyelenggarakan Pendidikan Singkat bagi anak Pengungsi di Rudenim Jakarta.

\section{Dokumen Hukum}

Undang-Undang Dasar Republik Indonesia Tahun 1945.

Undang- Undang Nomor 5 Tahun 1998 Tentang Pengesahan Konvensi Menentang Penyiksaan dan Perlakuan Lain yang Kejam, Tidak Manusiawi, atau Merendahkan Martabat Manusia.

Undang-Undang No 37 Tahun 1999 Tentang Hubungan Luar Negeri.

Undang-Undang No 12 Tahun 2005 Tentang pengesahan Konvensi Hak Sipil dan Politik

Undang-Undang Nomor 6 Tahun 2010 Tentang Keimigrasian.

Peraturan Dirjen Imigrasi Nomor: IMI-1489.UM.08.05 Tahun 2010 Tentang Penanganan Imigran Ilegal.

Konvensi Tahun 1951 Tentang Status Pengungsi.

Protokol Tambahan Tahun 1967 Tentang Pengungsi. 